\title{
PRODUCCIÓN DE BIOFERTILIZANTES UTILIZANDO Pseudomonas sp.
}

\section{BIOFERTILIZERS PRODUCTION USING Pseudomonas sp.}

\author{
Nery Santillana Villanueva ${ }^{1}$
}

\section{Resumen}

Con el objetivo de producir biofertilizantes utilizando 3 cepas de Pseudomonas sp., se realizaron tres experimentos: el primero, para encontrar un medio de cultivo apropiado para la multiplicación de las bacterias; el segundo, para determinar la sobrevivencia de las cepas de Pseudomonas sp en los biofertilizantes y el tercero para determinar la dosis eficiente de aplicación del biofertilizante en frijol, maíz, papa y tomate, en condiciones de invernadero. Al evaluar los resultados, se determinó que el medio de cultivo utilizado para la multiplicación de cepas de Pseudomonas sp., puede ser reemplazado por otros medios de cultivo de menor costo. La viabilidad de las cepas de Pseudomonas sp. en el inoculante fue similar hasta los 3 meses de conservación, garantizándose su uso hasta esa fecha. No se encontró diferencias significativas entre las dosis de biofertilizante aplicados a las plantas de frijol (Phaseolus vulgaris L.), maíz (Zea mays), papa (Solanum tuberosum L.) y tomate (Lycopersicon esculentum Mill.). La materia seca de la parte aérea y de la raíz de plantas de frijol y maíz inoculadas con las cepas de Pseudomonas sp. superaron con diferencias significativas al control sin inocular. En papa y tomate, no se encontraron diferencias significativas con el control.

Palabras Claves: Biofertilizantes, Pseudomonas sp., dosis de aplicación

\begin{abstract}
With the objective of producing biofertilizers using 3 Pseudomonas sp. strains, three experiments were carried out: first, to find appropriate culture means for bacteria multiplication, second to determine Pseudomonas sp. strain survival in the biofertilizer and third, to determine the efficient dose of biofertilizer application in beans (Phaseolus vulgaris L.), corns (Zea mays), potatoes (Solanum tuberosum L.) and tomatoes (Lycopersicon esculentum Mill) under greenhouse conditions. When evaluating the results, it was determined that the culture used for the Pseudomonas sp. multiplication, could be replaced by another lower cost culture. Pseudomonas sp. strain viability in the biofertilizer was similar during 3 months of conservation, so its use can be guaranteed until that date. Non significant differences were found between the biofertilizer applied doses to beans, corns, potatoes and tomatoes. Shoots and roots dry matter of beans and corn plants inoculated with Pseudomonas sp. strains differed significantly compared to control plants. Potato and tomato plants inoculated with Pseudomonas sp. did not differ significantly compared to non-inoculated control plants.
\end{abstract}

Key words: Biofertilizer, Pseudomonas sp., application dose

\section{Introducción}

El efecto de las actividades agrícolas en la degradación de los recursos naturales (erosión del suelo, uso de agroquímicos, etc.) es evidente en varias regiones de nuestro país, y debe ser evitado o por lo menos controlado. El uso de inoculantes biológicos (biofertilizantes), la incorporación de enmiendas orgánicas, las prácticas agrícolas que tienden a la conservación del suelo, la rotación de cultivos y el uso de leguminosas de cobertura, entre otras prácticas, pueden a largo plazo, contribuir a la recuperación de las poblaciones microbianas del suelo y con ello mejorar la calidad de este recurso (Cardoso et al., 1992; Siquiera \& Franco, 1998; Lindsey \& Jones, 1992). Los resultados de innumerables estudios, junto con la toma de conciencia sobre los efectos adversos de los pesticidas químicos, propiciaron el resurgimiento a escala mundial de la investigación sobre el uso de inoculantes bacterianos para controlar patógenos y mejorar el crecimiento vegetal. De esta manera se utilizan organismos naturales (rizobacterias) para reducir los efectos de organismos indeseables (patógenos) y así favorecer la producción de cultivos vegetales (Siquiera \& Franco, 1988; Pérez et al., 2000). Se conoce un gran número de bacterias de vida libre o asociativas que destacan por su potencial como biofertilizantes (Diaz et al., 2001; Zago et al., 2000), entre las que se encuentran las Pseudomonas. Los efectos positivos que ejercen estas bacterias en las plantas radican en que producen y segregan reguladores del crecimiento de plantas como auxinas, giberelinas y citoquininas, mejorando procesos como germinación de semillas, nutrición 
mineral, desarrollo de raíces, empleo del agua, entre otros (Pan et al., 1999).

En tal sentido, se realizó el presente trabajo de investigación con el objetivo general de producir biofertilizantes utilizando cepas de Pseudomonas sp. y con los siguientes objetivos específicos:

- Evaluar la multiplicación de tres cepas de Pseudomonas sp. en diferentes medios de cultivo.

- Evaluar la sobrevivencia de las cepas de Pseudomonas sp. en soporte a base de turba.

- Determinar la dosis apropiada de aplicación del biofertilizante en plantas de maíz, frijol, papa y tomate, en condiciones de invernadero.

\section{Materiales y métodos}

El trabajo de investigación se realizó en el laboratorio e invernadero del Área de Investigación de Rhizobiología, del Programa de Investigación en Pastos y Ganadería de la Facultad de Ciencias Agrarias de la Universidad Nacional de San Cristóbal de Huamanga - Ayacucho, ubicado a $2750 \mathrm{msnm}$ Las cepas de Pseudomonas sp. utilizadas en el experimento, fueron aisladas y caracterizadas en trabajos anteriores realizados en el mismo laboratorio. El presente trabajo comprendió tres experimentos, los que se indican a continuación:

Experimento 1: Multiplicación de Pseudomonas sp. en diferentes medios de cultivo.

Se consideró cuatro medios de cultivo (Tabla 1) y tres cepas de Pseudomonas sp.: C1, C2 y C3. Cada una de las cepas fueron reactivadas en tubos con agar nutritivo. A partir de los cultivos reactivados, se tomó una asada y se sembró en balones de 1 litro de capacidad con $500 \mathrm{ml}$ de medio de cultivo. Los balones se incubaron a temperatura de ambiente $\left(20^{\circ} \mathrm{C}\right)$. A las 24 y 48 horas de incubación se realizó la evaluación del crecimiento bacteriano, utilizando el método de dilución y siembra en placas con medio agar nutritivo. Las placas sembradas se incubaron a temperatura de ambiente y a las 48 horas se realizó el recuento de colonias.

Experimento 2: Sobrevivencia de Pseudomonas sp. en soporte.

Las cepas de Pseudomonas sp fueron multiplicadas en caldo nutritivo e incubadas durante 48 horas. Los biofertilizantes fueron preparados utilizando la técnica descrita por Santillana et al. (1998). Se consideró 2 repeticiones por cepa. La evaluación del número de bacterias por gramo de biofertilizante, se realizó utilizando el método de dilución y siembra en medio de cultivo. Los resultados fueron evaluados mediante el ANVA en un experimento factorial de $3 \mathrm{~A} \times 3 \mathrm{~B} \times 2$ repeticiones, donde A representa las cepas (C1, C2 y C3) y B los periodos de evaluación (después de la maduración, al mes y a los tres meses de conservación).
Experimento 3: Determinación de la dosis apropiada de biofertilizante para la aplicación a plantas de frijol, maíz, papa y tomate en condiciones de invernadero.

Tabla 1. Composición de medios de cultivo utilizados para la multiplicación de tres cepas de Pseudomonas sp.

\begin{tabular}{|c|c|c|c|c|}
\hline \multirow{2}{*}{$\begin{array}{l}\text { Componentes } \\
\qquad(\mathrm{gr} / \mathrm{ml})\end{array}$} & \multicolumn{4}{|c|}{ Medios de cultivo } \\
\hline & M1 & M2 & M3 & M4 \\
\hline Peptona & 10 & 5 & 2,5 & - \\
\hline $\begin{array}{l}\text { Cloruro de } \\
\text { sodio }\end{array}$ & 5 & 5 & 5 & 5 \\
\hline $\begin{array}{l}\text { Extracto de } \\
\text { carne }\end{array}$ & 3 & 1,5 & - & - \\
\hline $\begin{array}{l}\text { Extracto de } \\
\text { levadura }\end{array}$ & - & - & 1 & 1 \\
\hline Sacarosa & - & - & - & 5 \\
\hline $\begin{array}{l}\text { Fosfato de } \\
\text { potasio }\end{array}$ & 0,3 & - & - & 0,3 \\
\hline
\end{tabular}

Para cada especie de planta se consideró tres dosis de biofertilizante $(0.5 ; 1.0$ y 2.0 gramos de biofertilizante por planta), un control sin inocular y un control con fertilización química. Se utilizó suelo de Pampa del Arco, el que se limpió y abonó con 60 unidades de roca fosfórica. Para el tratamiento con fertilización química se utilizó superfosfato triple $\mathrm{y}$ urea (80 - 80 - 0 de NPK). El suelo preparado se colocó en maceteros de $3 \mathrm{~kg}$ de capacidad, luego se humedecieron a capacidad de campo. En cada macetero se consideró una planta, la que fue inoculada con las respectivas dosis. El experimento por especie de planta fue conducido en el diseño completamente al azar con tres repeticiones por tratamiento. Los resultados de la materia seca de la parte aérea y de la raíz fueron evaluados mediante el análisis de variancia, la prueba de significación de Duncan $(\mathrm{p}<$ 0.05) y la determinación del Índice de Efectividad de la Inoculación (IEI).

\section{Resultados y discusión}

Experimento 1: Multiplicación de Pseudomonas sp. en diferentes medios de cultivo.

El Análisis de Variancia del logaritmo del número de bacterias por ml de medio, mostró diferencias altamente significativas entre medios de cultivo, entre horas de evaluación y en la interacción medios por horas (AxC) y diferencias significativas en la interacción medios por cepas (AxB). Por lo que se procedió al estudio de los efectos simples de las interacciones $\mathrm{AxB}$ y AxC. El ANVA para el estudio de los efectos simples de los factores A y C mostró diferencias altamente significativas de los medios de cultivo en las cepas C1 y C3; asimismo, entre horas en los medios M1, M2, M3 y M4.

Al realizar la Prueba de Duncan $(\mathrm{p}<0.05)$ de las diferencias de los medios de cultivo en la Cepa 1 
(C1)(Tabla 2) se observó que los medios de cultivo 1 y 2 superaron con diferencias significativas a los medios 3 y 4, indicando que el medio control (M1) puede ser reemplazado por el medio 2 (M2) que tiene $50 \%$ de peptona y extracto de carne, abaratando de esta manera los costos de producción. La cepa 3 (C3) puede ser multiplicada de preferencia en el medio 1 , aunque no presentó diferencias significativas con los medios 2 y 4, sin embargo, superó significativamente al medio 3. La cepa 2 (C2) puede ser multiplicada en cualquiera de los medios de cultivo, es decir el medio control puede ser reemplazado. Los medio 3 y 4 aún son de menor costo. El medio 3 (M3) presenta sólo $25 \%$ de peptona, en lugar de extracto de carne presenta extracto de levadura. El medio 4 (M4) no presenta peptona, ni extracto de carne, sólo extracto de levadura y sacarosa y fosfato de potasio.

Tabla 2. Prueba de Duncan $(\mathrm{p}<0.05)$ del $\log \mathrm{n}^{\circ}$ de bacterias/ml de tres cepas de Pseudomonas sp. en los diferentes medios de cultivo.

\begin{tabular}{cccc} 
& \multicolumn{3}{c}{ Log. del número de bacteria/ ml } \\
\cline { 2 - 4 } $\begin{array}{c}\text { Medio de } \\
\text { cultivo }\end{array}$ & Cepa 1 & Cepa 2 & Cepa 3 \\
\hline Medio 1 & $4.05 \mathrm{a}$ & $4.06 \mathrm{a}$ & $4.25 \mathrm{a}$ \\
Medio 2 & $4.18 \mathrm{a}$ & $3.68 \mathrm{a}$ & $3.94 \mathrm{ab}$ \\
Medio 3 & $3.56 \mathrm{~b}$ & $3.95 \mathrm{a}$ & $3.58 \mathrm{~b}$ \\
Medio 4 & $3.45 \mathrm{~b}$ & $3.81 \mathrm{a}$ & $3.79 \mathrm{ab}$ \\
\hline
\end{tabular}

Tabla 3. Prueba de Duncan $(p<0.05)$ del log número de bacterias/ml de tres cepas de Pseudomonas sp. en diferentes medios de cultivo, evaluados a las 24 y 48 horas de incubación.

\begin{tabular}{lcccc}
\hline Tiempo de & \multicolumn{4}{c}{ Log. del número de bacterias/ml } \\
\cline { 2 - 5 } Incubación & Medio 1 & Medio 2 & Medio 3 & Medio 4 \\
\hline 24 Horas & $3.18 \mathrm{a}$ & $3.18 \mathrm{a}$ & $3.13 \mathrm{a}$ & $3.13 \mathrm{a}$ \\
48 Horas & $5.08 \mathrm{~b}$ & $4.69 \mathrm{~b}$ & $4.26 \mathrm{~b}$ & $4.24 \mathrm{~b}$ \\
\hline
\end{tabular}

En la Tabla 3, se observa, en todos los casos, que el número de bacterias obtenido a las 48 horas superó significativamente al número de bacterias de las 24 horas. Estos resultados indican que el cultivo de las 48 horas debe ser utilizado para la mezcla con el soporte. Experimento 2: Sobrevivencia de Pseudomonas sp. en soporte.

Al realizar el Análisis de Variancia de la sobrevivencia de las cepas de Pseudomonas sp. en soporte a base de turba, evaluada después del periodo de maduración, al mes y a los 3 meses de conservación, no se encontró diferencias significativas en ninguna de las fuentes de variación, es decir entre cepas (A1, A2 y A3), entre periodos de evaluación (B1, B2 y B3) y en la interacción cepas por periodos de evaluación (A x B). Los resultados indican que la viabilidad de las tres cepas fue semejante hasta los tres meses de conservación del inoculante (Tabla 4), por lo que se podría recomendar su uso hasta los tres meses sin problemas de pérdida de viabilidad.

Tabla 4. Sobrevivencia de cepas de Pseudomonas sp. a través del tiempo.

\begin{tabular}{rccc}
\hline \multirow{2}{*}{ Cepas } & \multicolumn{3}{c}{ Log. del número de bacterias/g } \\
\cline { 2 - 4 } & Después de & Un & Tres \\
& maduración & Mes & Meses \\
\hline Cepa 1 & 6.60 & 6.29 & 5.46 \\
Cepa 2 & 6.42 & 6.47 & 6.18 \\
Cepa 3 & 6.52 & 6.64 & 6.35 \\
\hline
\end{tabular}

Experimento 3: Det erminación de la dosis apropiada de biofertilizant e para la aplicación a plantas de frijol, maíz, papa y tomate, en condiciones de invernadero.

En frijol y maíz la Prueba de Duncan $(\mathrm{p}<0.05)$ de la materia seca de la parte aérea (Tabla 5) mostró que las dosis 2, 1 y 0.5 gramos y la fertilización química (FQ) superaron con diferencias significativas al control sin inocular, observándose incrementos entre 51 y 59\% en frijol y entre 77 y 99\% en maíz. En papa y tomate, los tratamientos con las diferentes dosis de inoculación fueron similares al control sin inocular.

En todos los cultivos evaluados, no se encontró diferencias significativas entre dosis de inoculación, indicando que puede utilizarse $0.5,1$ ó 2 gramos de inoculante por planta.

Los efectos positivos observados en frijol y maíz sugieren que posiblemente existió un sinergismo entre el hospedante y las bacterias, que junto con las fitohormonas que excretan las raíces provocaron el mayor desarrollo de la parte aérea de las plantas señaladas Así lo reportaron Dashti et al. (1997), Gutierrez-Zamora \& Martinez-Romero (2001), Mayak et al. (2004) quienes al inocular rizobacterias promotoras del crecimiento, encontraron mayor desarrollo de la parte aérea de plantas de soya, maíz y tomate, respectivamente. Mientras que el bajo o nulo efecto de Pseudomonas sp. en las plantas de papa y tomate pudo deberse a que las cepas no encontraron el medio adecuado en la rizósfera de éstas plantas (Alexander, 1980).

$\mathrm{Al}$ evaluar la materia seca de las raíces, se observó en todos los casos, incrementos con relación al control sin inocular. En maíz y frijol, el desarrollo de las raíces, favorecido por efecto de la inoculación de Pseudomonas sp se manifestó en mayor crecimiento de la parte aérea del cultivo. Estos resultados concuerdan con los reportados por Pereira et al. (1988) y Santillana (2001) quienes observaron incrementos en el desarrollo radicular de diferentes plantas como sorgo, arroz y trébol cuando fueron 
inoculadas con rizobacterias, lo que repercute directamente en el rendimiento del cultivo.

Tabla 5. Prueba de Duncan $(\mathrm{p}<0.05)$ e Indice de Efectividad de la Inoculación (IEI) de la Materia seca de la parte aérea y de la raíz de plantas de Frijol var. Panamito, Maíz amiláceo, Papa var. Canchán y Tomate var. Río Grande inoculadas con diferentes dosis de biofertilizante.

\begin{tabular}{|c|c|c|c|c|c|}
\hline \multirow[t]{2}{*}{ Cultivos } & \multirow{2}{*}{$\begin{array}{l}\text { Tratamien- } \\
\text { tos }\end{array}$} & \multicolumn{2}{|c|}{$\begin{array}{c}\text { Materia Seca Parte } \\
\text { Aérea (gr) }\end{array}$} & \multicolumn{2}{|c|}{$\begin{array}{l}\text { Materia Seca Raíz } \\
\text { (gr) }\end{array}$} \\
\hline & & $\begin{array}{c}\text { Duncan } \\
(\mathrm{p}<0.05)\end{array}$ & IEI \% & $\begin{array}{l}\text { Duncan } \\
(\mathrm{p}<0.05)\end{array}$ & IEI \% \\
\hline \multirow{5}{*}{ Frijol } & Dosis 0.5 & $10.30 \mathrm{a}$ & 53 & $0.25 \mathrm{a}$ & 25 \\
\hline & Dosis 1.0 & $10.53 \mathrm{a}$ & 57 & $0.23 \mathrm{a}$ & 15 \\
\hline & Dosis 2.0 & 10.68 a & 59 & $0.22 \mathrm{a}$ & 10 \\
\hline & Fert.Química & 10.11 a & 51 & $0.20 \mathrm{a}$ & \\
\hline & Control & $6.71 \mathrm{~b}$ & & $0.20 \mathrm{a}$ & \\
\hline \multirow{5}{*}{ Maíz } & Dosis 0.5 & 23.12 a & 77 & $3.77 \mathrm{a}$ & 110 \\
\hline & Dosis 1.0 & $24.94 \mathrm{a}$ & 91 & $3.73 \mathrm{a}$ & 108 \\
\hline & Dosis 2.0 & 23.69 a & 82 & $3.27 \mathrm{a}$ & 83 \\
\hline & Fert.Química & 24.69 a & 90 & $3.28 \mathrm{a}$ & 83 \\
\hline & Control & $13.02 \mathrm{~b}$ & & $1.79 \mathrm{~b}$ & \\
\hline \multirow{5}{*}{ Рара } & Dosis 0.5 & $6.22 \mathrm{~b}$ & 7,0 & $1.55 \mathrm{abc}$ & 19 \\
\hline & Dosis 1.0 & $6.14 \mathrm{~b}$ & 6,5 & $1.61 \mathrm{ab}$ & 24 \\
\hline & Dosis 2.0 & $5.74 \mathrm{~b}$ & - & 1.47 bc & 13 \\
\hline & Fert.Química & $7.67 \mathrm{a}$ & 22 & $1.83 \mathrm{a}$ & 41 \\
\hline & Control & $6.00 \mathrm{~b}$ & & $1.30 \mathrm{c}$ & \\
\hline \multirow{5}{*}{ Tomate } & Dosis 0.5 & $17.22 \mathrm{~b}$ & - & $4.26 \mathrm{a}$ & 42 \\
\hline & Dosis 1.0 & $16.40 \mathrm{~b}$ & - & $4.19 \mathrm{a}$ & 40 \\
\hline & Dosis 2.0 & $17.16 \mathrm{~b}$ & - & $4.35 \mathrm{a}$ & 45 \\
\hline & Fert.Química & 33.19 a & 38 & $3.92 \mathrm{a}$ & 31 \\
\hline & Control & $20.50 \mathrm{~b}$ & & $3.00 \mathrm{~b}$ & \\
\hline
\end{tabular}

\section{Conclusiones y recomendaciones}

- El medio de cultivo utilizado para la multiplicación de las 3 cepas de Pseudomonas sp., puede ser reemplazado por otros medios de cultivo de menor costo.

- $\quad$ La cepa C1 puede ser multiplicada en el medio 2. La cepa C2 puede ser multiplicada en cualquiera de los medios de cultivo evaluados. La cepa C3 de preferencia en el medio 1 (control).

- $\quad$ Se determinó mayor número de bacterias a las 48 horas de incubación, número que superó con diferencias significativas a la viabilidad obtenida a las 24 horas.

- $\quad$ La viabilidad de las cepas de Pseudomonas sp en el inoculante fue similar hasta los 3 meses de conservación, garantizándose su uso hasta esa fecha.
- $\quad$ No se encontró diferencias significativas entre las dosis de biofertilizante aplicados a las plantas de frijol, maíz, papa y tomate.

- La materia seca de la parte aérea y de la raíz de plantas de frijol y maíz inoculadas con las cepas de Pseudomonas sp. superaron con diferencias significativas al control sin inocular. En el caso de papa y tomate, no se encontró diferencias significativas con el control.

- $\quad$ En frijol se encontró incrementos de 53 a 59\% de la parte aérea y de 10 a $25 \%$ de la raíz. En maíz, 77 a $91 \%$ de la parte aérea y de 83 a $110 \%$ de la raíz. En papa entre 2 a $4 \%$ de la parte aérea y de 13 a $24 \%$ de la raíz. En tomate, se observó 40 a $45 \%$ de incremento de la raíz, no hubo incremento en la parte aérea.

- Se recomienda, continuar aislando y seleccionando cepas de Pseudomonas sp. eficientes en diferentes plantas de interés agrícola.

- Las cepas seleccionadas deben ser evaluadas a nivel de campos experimentales.

\section{Agradecimientos}

A la Raaa (Red de Acción en Alternativas al Uso de Agroquímicos) por el apoyo económico brindado. A la Universidad Nacional de San Cristóbal de Huamanga a través de la Facultad de Ciencias Agrarias por las facilidades brindadas para la ejecución y culminación del presente trabajo de investigación. A la Universidad Nacional de Huancavelica, gestora del apoyo económico.

\section{Literatura citada}

Alexander M. 1980. Introducción a la Microbiología del suelo. AGT. Edit. S.A. México.

Cardoso E., Siu T. \& Neves M. 1992. Microbiología do Solo. Sociedade Brasileira de Ciencia do Solo. Campinas, Brasil.

Dashti N., Zhang R., Hynes R. \& Smith D. 1997. Application of plant growth-promoting rhizobacteria to soybean (Glycine max (L.) Merr.) increases protein and dry matter yield under shortseason condition. Plant Soil. 188: 33-41.

Díaz P., Ferrera-Cerrato R., Almaraz-Suárez J. \& Alcántara G. 2001. Inoculation of Plant Growthpromoting Bacteria in Lettuce. Terra. 19: 327-33

Gutierrez-Zamora A. \& Martinez-Romero E. 2001. Natural endophytic association between Rhizobium ettli and maize (Zea mays L.). Journal of Biotechnology. 91: 117-126.

Lindsey K. \& Jones M. 1992. Biotecnología Vegetal Agrícola. Editorial Acribia S.A. España.

Mayak S., Tirosh T. \& Glick B. 2004. Plant growthpromoting bacteria confer resistance in tomato plants to salt stress. Plant Physiology and Biochemistry. 42: 565-572.

Pan B., Bai Y., Leibovitch S. \& Smith D. 1999. Plantgrowth promoting rhizobacteria and kinetin as 
ways to promote corn growth and yield in a shortgrowing-season area. European Journak of Agronomy. 11: 179-186.

Pereira J., Cavalcante V., Baldani J. \& Dobereiner J. 1988. Sorghum and rice inoculation with Azospirillum sp. and Herbaspirillum seropedicae in field. Plant Soil. 110: 269-274.

Pérez C., De La Fuente L., Arias A. \& Altier N. 2000. Uso de Pseudomonas fluorescentes nativas para el control de enfermedades de implantación en Lotus corniculatus L. Agrociencia. IV (1): 41-47.

Santillana N. 2001. Efecto de la Biofertilización en el crecimiento de Trifolium repens y Lolium multiflorum en condiciones de invernadero. En: Vilca, J. (Edit). 2001. Investigación. (9). ISSN 1684-0089.
Santillana N., Freire J.R.J., Sá, E.L.S. \& Sato M. 1998. Avaliação de estirpes de Rizóbio para a produção de inoculantes para trevo vermelho. R. Bras. Ci. Solo. 22(2): 231-37.

Siquiera O. \& Franco A. 1988. Biotecnología del suelo. Fundamentos y perspectivas para las Ciencias Agrarias en los Trópicos Brasileños. Escuela Superior de Agricultura de Lavras, Brasil.

Zago V., De-Polli H. \& Rumjanek N. 2000. Pseudomonas spp. Fluorescentes - Bacterias promotoras de crescimento de plantas e biocontroladoras de fitopatógenos em sistemas de produção agrícola. Seropédica: EMBRAPA Agrobiología. 32p. EMBRAPA-CNPAB, Documento $N^{\circ}$ 127. SIN 0104-6187.

${ }^{1}$ Laboratorio de Rhizobiología, Universidad Nacional de San Cristóbal de Huamanga . Portal Independencia N ${ }^{\circ}$ 57 Ayacucho-Perú. nerysantillana@yahoo.es 